DOI: 10.12731/2077-1770-2018-4-236-246

УДК 812

\title{
СТРУКТУРА СИНТАГМАТИЧЕСКИХ ОТНОШЕНИЙ В СЛОВООБРАЗОВАТЕЛЬНОМ ГНЕЗДЕ С ВЕРШИНОЙ БУГ В ЭВЕНСКОМ ЯЗЫКЕ
}

Нестерова Е.В.

Цель. Статья посвящена малоизученной в эвеноведении теме словообразовательных гнезд. Предметом анализа выступают словообразовательные иепи с исходным словом буг. Автор ставит иелью, раскрыть структуру словообразовательного гнезда с вершиной буг по горизонтальной оси.

Метод или методология проведения работы. Основным методом исследования служстт описательный; использованы методы словообразовательного и семантического анализа.

Результаты. В статье установлен деривационный объем словообразовательного гнезда с вершиной буг в эвенском языке. Выявлены бинарные и полинарные словообразовательные цепи. Словообразовательное гнездо характеризуется значительным количеством полинарных иепей, большую часть из которых занимают пятикомпонентные. Наиболее высокой дериваиионной продуктивностью в гнезде отличается производное первой ступени словообразования буй.

Область применения результатов. Результаты работы могут быть применены в исследованиях по синхронному словообразованию в тунгусо-маньчжурских языках.

Ключевые слова: словообразовательное гнездо; словообразовательная цепь; полинарные иепи; ступени словообразования; дериватыз; суффиксы.

\section{STRUCTURE OF SYNTAGMATIC RELATIONS IN THE FORMATIVE FAMILIES WITH THE BUG TOP IN THE EVEN LANGUAGE}

\section{Nesterova E.V.}

Purpose. The article is devoted to the insufficiently studied subject of formative families in the Even language. The subject of the analysis 
are word-formative chains with the original word bug. The author aims to reveal the structure of the formative families with the top of the bug on the horizontal axis.

Methodology. The main method of research is the descriptive one, along with the methods of word-formation and semantic analysis.

Results. The article establishes the derivational volume of the formative families with the bug top in the Even language. Both binary and polynary derivational chains are revealed. Formative families are characterized by a significant number of polynary chains, most of which being five-component ones. The derivative of the first stage of the buy lexeme formation is characterized by the highest derivative productivity in the formative family.

Practical implications. The results of the work can be used in studies of synchronous word formation of the Tungus-Manchurian languages.

Keywords: formative families; derivational chain; polynary chain; steps of word formation; derivatives; suffixes.

Эвенский язык, именовавшийся ранее в литературе также ламутским, относится к северной подгруппе тунгусо-маньчжурской семьи языков, которая и типологически, и материально (по ряду грамматических признаков и по составу лексики) может быть включена вместе с монгольскими, тюркскими, корейским и некоторыми другими языками в более обширную семью алтайских языков [4, с. 3$]$.

Вопросам словообразования в эвенском языке посвящено много работ. Большое внимание в них уделяется способам словообразования частей речи эвенского языка $[1 ; 3 ; 4 ; 5 ; 8 ; 13,14]$, слов различных лексико-семантических групп [9], функционированию отдельных суффиксов [2] и др. Изучение словообразовательных отношений на уровне словообразовательных гнезд является новым направлением в эвенской лингвистике. Предлагаемая работа посвящена исследованию структуры словообразовательного гнезда с вершиной буг «1) местность; страна; земля; 2) мир; вселенная; 3) место; 4) родина; 5) природа; 6) поле, тайга» [10, с. 100]. 
Теоретической базой исследования послужили труды знаменитых российских и зарубежных ученых А.Н. Тихонова [11], И.А. Ширшова [15], Н.В. Пятаевой [6], В.Г. Фатхутдиновой [12], J. Bölte, P. Zwitserlood, B.M. Jansma, A. Zilverstand [16], R. Morin [17], M. Singson, D. Mahony, V. Mann [18], S.Z. Riehemann [19], Ju. Uriagereka [20] и др. В качестве материала использованы “Сравнительный словарь тунгусо-маньчжурских языков» [10], «Эвенско-русский словарь” [7] и полевые материалы автора.

Придерживаясь определения А.Н. Тихонова, под словообразовательным гнездом, мы понимаем упорядоченную отношениями прозводности совокупность слов, характеризующуюся общностью корня [11, с. 36].

Структура словообразовательного гнезда определяется соотношением единиц двух планов - синтагматического и парадигматического. В синтагматическом плане словообразовательное гнездо представляет собой совокупность словообразовательных цепочек, а в парадигматическом плане - совокупность словообразовательных парадигм [Там же, с. 41].

В настоящей работе структуру словообразовательного гнезда с вершиной буг мы предлагаем рассмотреть через систему синтагматических связей. Для этого нам предстоит выявить и разобрать все словообразовательные цепи в гнезде с вершиной буг. Словообразовательная цепь - это ряд однокоренных слов, связанных между собой отношениями последовательной производности. Словообразовательная цепь может включать разное количество однокоренных слов и объединять слова разных частей речи. Исходное слово цепи (оно же и исходное слово гнезда) является непроизводным и выполняет функцию производящего [Там же].

Изучение последовательной производности слов от исходного буг выявило сорок словообразовательных цепей. По мнению И.А. Ширшова, по своей структуре словообразовательные цепи делятся на бинарные и полинарные [15, с. 178]. Бинарные цепи состоят из двух компонентов - исходного слова и одного производного. В состав полинарных цепочек входят три и более компонента. В на- 
шем гнезде насчитывается всего пять бинарных цепей, состоящих из одного производящего и одного производного:

буг/а/лкан «имеющий родину»

буг/a/т/тай «1) жить в определенно месте; 2) иметь родину»

БУГ буг/и/лта «1. отдельный, 2.1) в сторону друг от друга;

2) отдельно».

буг/и/п/тай «отделиться (от коллектива)»

буй «1.1) дикое, глухое, нежилое место (лес, тайга, тундра);

2) поле, лес, пустыня; 3) местность, отдаленная от дома;

2.1) дикий (о местности), нежилой (лесной, таежный, тундровый); 2) отдаленный от дома; нежилой; 3. в стороне от жилья» [10, с. 100].

Здесь, на первой ступени деривации образованы два глагола, существительное, прилагательное и наречие. Все дериваты, как и другие производные в гнезде, образованы путем суффиксации, которая является основным способом словообразования в эвенском языке. Суффиксы в слове располагаются в строго определенном порядке: “Сначала, вслед за корнем, следуют суффиксы словообразовательные; за ними, в именах, могут идти показатели субъективной оценки или показатели особых форм логико-грамматических отношений; далее следуют показатели множественного числа, падежа и принадлежности. В глаголах, вслед за суффиксами словообразовательными, например в отыменных глаголах, или за суффиксами залога и вида, идут показатели времени или наклонения и лица. Наконец, составляя со словом одно фонетическое целое, могут присоединяться частицы. Таким образом, слово может включать в себя по нескольку суффиксов разнообразного значения» [13, с. 10].

Преобладающим большинством в словообразовательном гнезде с вершиной буг обладают полинарные словообразовательные цепи, имеющие от трех и более компонентов. Меньшую часть полинарных цепей составляют трехкомпонентные. Их в гнезде всего пять:

буи/г «лесной, таежный, находящийся в тайге, в стороне от жилья». 
БУГ $\rightarrow$ БУЙ $\quad$ буи/н междом. «прочь!»

буи/н «1.1) дикое, нежилое место (лес, тайга, тундра); 2) поле; 2.1) дикий (о местности), нежилой».

буй/гида «дикая, нежилая (лесная, таежная, тундровая) сторона»

бую/дэй «идти на охоту».

На данной (второй) ступени словообразования расположились существительное, прилагательное, глагол, наречие и междометие. Все дериваты образованы от производящего буй.

Следующей по восхождению является четырехкомпонентная словообразовательная цепь. В нашем гнезде таких цепей двенадцать. На второй ступени словообразования они имеют производное буюдэй:

бую/вкэн/дэй «отправить на охоту».

бую/вэн/дэй «изредка охотиться».

бую/грэ/дэй «охотиться».

бую/дек «сборы, приготовление к охоте».

бую/ден/дэй «нехотя охотиться»

бую/дь «1. отправившийся на охоту; 2. охотник; 3. охотничий».

бую/мэ/дэй «отправиться на охоту».

бую/н «1. дикий олень; 2. дикий».

бую/нэ/дэй «отправиться на охоту».

БУГ $\rightarrow$ БУЙ $\rightarrow$ БУЮДЭЙ бую/с/тэй «охотиться, промышлять, добывать, ловить зверя»»».

бую/счи/дэй «пытаться охотиться»

бую/сэк «1) охота, промысел; 2) место охоты».

Таким образом, третья ступень деривации представлена глагольным блоком, состоящим из одной залоговой и семи видовых форм, а также четырьмя отглагольными существительными.

Подавляющее большинство словообразовательных цепей составляют пятикомпонентные, которых в гнезде семнадцать. Из них одиннадцать имеют в третьей ступени производное буюстэй: 
бую/с/кич «место охоты, промысла».

бую/с/нэс/тэй «сходить, съездить охотиться».

бую/с/си «1. охотник, зверолов; 2 . охотничий, звероловный».

БУГ $\rightarrow$ БУЙ $\rightarrow$ БУЮДЭЙ $\rightarrow$ БУЮСТЭЙ бую/с/э/лдывун «1. охотничье, промысловое орудие, охотничий промысловый инвентарь; 2. охотничий, промысловый».

бую/с/э/л/дэй «начать охотиться».

бую/c/э/лэн «хороший, удачливый охотник».

бую/с/э/мдэ «охотничий, промысловый».

бую/с/э/мкин «дорога к месту охоты, промысла».

бую/с/э/мңэ «1. охотник, зверолов; 2. охотничий, звероловный».

бую/с/э/н «1. охота, промысел, добыча, ловля; 2. охотничий, промысловый».

бую/с/э/нмэй «1. охота, промысел, добыча, ловля; 2. охотничий, промысловый».

На данной ступени словообразования, большую часть дериватов составляют имена: семь существительных, два прилагательных и только две видовые формы глагола.

Вторая ветвь пятикомпонентных цепей, имеющая в третьей ступени существительное буюн, имеет три деривата, из которых два существительных и один глагол:

бую/ми/дэй «охотиться (на дикого оленя)».

БУГ $\rightarrow$ БУЙ $\rightarrow$ БУЮДЭЙ $\rightarrow$ БУЮН бую/нэ/н «олень-полукровка

(помесь домашнего и дикого оленя)».

бую/рэ «дикий олень».

У остальных пятикомпонентных цепей совпадают первые три компонента:

Буг $\rightarrow$ буй $\rightarrow$ бую/дэй $\rightarrow$ бую/нэ/дэй $\rightarrow$ Буг $\rightarrow$ буй $\rightarrow$ бую/дэй $\rightarrow$ бую/счи/дэй $\rightarrow$ бую/счи/л/дэй «охотиться, промышлять, добывать, ловить зверя».

Буг $\rightarrow$ буй $\rightarrow$ бую/дэй $\rightarrow$ бую/дек $\rightarrow$ бую/сэ/дек «1) охота, промысел; 2) место охоты». 
Единственная в гнезде словообразовательная цепь является шестикомпонентной:

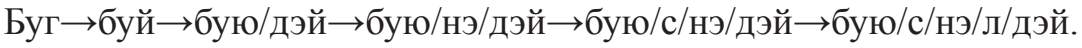

Таким образом деривационный объем словообразовательного гнезда с вершиной буг в эвенском языке составляет сорок производных. Наибольшую часть дериватов представляет именной блок: существительные (шестнадцать), прилагательные (четыре); глагольный блок состоит из инфинитива (один), видовых форм (пятнадцать), залоговых форм (один); меньшее количество мотивированных слов составляют наречия (два), междометие (один). Основным деривационным ядром в словообразовательном гнезде с вершиной буг является производное первой ступени - имя существительное буй.

В синтангматическом плане словообразовательное гнездо с вершиной буг состоит из сорока словообразовательных цепей, причем большая часть цепей являются полинарными (тридцать пять), состоящими от трех до шести компонентов. Пятикомпонентные словообразовательные цепи по количеству преобладают над остальными (семнадцать).

Исследование ступеней деривации выявило следующее: производные первых двух ступеней словообразования разнородны по частеречной принадлежности, на третьей ступени большую часть производных составляют видовые формы глагола, большинство производных четвертой ступени относятся к именным частям речи: существительные и прилагательные, в пятой ступени всего лишь одно производное, которое представляет видовую форму глагола.

\section{Список литературы}

1. Дуткин Х.И. Аллаиховский говор эвенов Якутии. СПб.: Наука. 1996. 207 c.

2. Кузьмина Р.П. Функционирование суффикса -кан в эвенском языке. Альманах современной науки и образования. 2013. № 6 (73). С. 93-94.

3. Лебедев В.Д. Язык эвенов Якутии. Л.: Наука, 1978. 208 с. 
4. Новикова К.А. Очерки диалектов эвенского языка. Ольский говор. Л.: Наука, 1980. 162 с.

5. Попова М.Д. Словообразование прилагательных в эвенском языке // Филологические науки. Вопросы теории и практики. 2017. №7 (73). C. 166-168.

6. Пятаева Н.В. Еще раз о словообразовательном гнезде // Актуальные проблемы филологии и педагогической лингвистики, 2016, №3. C. $13-17$.

7. Роббек В.А., Роббек М.Е. Эвенско-русский словарь. Новосибирск: Наука, 2005. 353 с.

8. Роббек В.А. Язык эвенов Березовки. Л.: Наука, 1989. 204 с.

9. Саввинова С.Н. Словообразование заимствованной лексики в эвенском языке // Общественные науки. 2017. № 2-2. С. 375-378.

10. Сравнительный словарь тунгусо-маньчжурских языков. Материалы к этимологическому словарю. Том І. Л: Наука. 1975. 672 с.

11. Тихонов А.Н. Основные понятия русского словообразования // Словообразовательный словарь русского языка: в 2 т. Т.1. М.: Рус. яз., $1985.856 \mathrm{c}$.

12. Фатхутдинова В.Г. Последовательная производность как универсальное свойство словообразовательных систем русского и татарского языков // Ученые записки Казанского государственного университета. Гуманитарные науки. Том 148, кн. 3. 2006. С. 154-160.

13. Цинциус В.И. Очерк грамматики эвенского (ламутского) языка. Фонетика и морфология. Л.: Государственное учебно-педагогическое издательство Министерства просвещения РСФСР. Ленинградское отделение, 1947. 270 с.

14. Шарина С.И. Отыменное глагольное словообразование в нижнеколымском говоре эвенского языка // The Scientific Heritage. 2017. Т. 2. № 9 (9). С. 123-125.

15. Ширшов И.А. Теоретические проблемы гнездования. М.: Прометей, 1999. $236 \mathrm{c}$.

16. Bölte J., Zwitserlood P., Jansma B.M., Zilverstand A. Derivational morphology approached with event-related potentials // Mental Lexicon, T. 4. no 3 (2009): 336-353. 
17. Morin R. Derivational Morphological Analysis as a Strategy for Vocabulary Acquisition in Spanish // The Modern Language Journal, T. 87. No 2 (2003): 200-221.

18. Singson M., Mahony D., Mann V. The Relation between Reading Ability and Morphological Skills: Evidence from Derivational Suffixes // Reading and Writing, T. 12. No 3-4 (2000): 219-252.

19. Riehemann S.Z. Type-based Derivational Morphology // The Journal of Comparative Germanic Linguistics, T. 2. No 1 (1998): 49-77.

20. Uriagereka Ju. Cutting Derivational Options // Natural Language \& Linguistic Theory, T. 19. No 4 (2001): 891-900.

\section{References}

1. Dutkin H.I. Allaihovskij govor jevenov Jakutii [Allaihivsky Dialect of the Yakutia Evens]. SPb.: Nauka, 1996. 207 p.

2. Kuz'mina R.P. Funkcionirovanie suffiksa -kan v jevenskom jazyke [The Functioning of the Suffix -kan in the Even Language]. Al'manah sovremennoj nauki i obrazovanija. 2013. No. 6 (73): 93-94.

3. Lebedev V.D. Jazyk jevenov Jakutii [The Language of the Yakutia Evens]. L.: Nauka, 1978. 208 p.

4. Novikova K.A. Ocherki dialektov jevenskogo jazyka. Ol'skij govor [Essays on the Dialects of the Even Language. The Olsk Language]. L.: Nauka, 1980. 162 p.

5. Popova M.D. Slovoobrazovanie prilagatel'nyh v jevenskom jazyke [Word Formation of Adjectives in Even Language]. Filologicheskie nauki. Voprosy teorii i praktiki. 2017. no 7-3 (73): 166-168.

6. Pjataeva N.V. Eshche raz o slovoobrazovatel'nom gnezde [Once Again about the Word Family]. Aktual'nye problemy filologii i pedagogicheskoj lingvistiki. 2016. No 3: 13-17.

7. Robbek V.A., Robbek M.E. Jevensko-russkij slovar'[The Even-Russian Dictionary]. Novosibirsk: Nauka, 2005. 353 p.

8. Robbek V.A. Jazyk jevenov Berezovki [The Language of the Evens of Berezovka]. L: Nauka, 1989. 204 p.

9. Savvinova S.N. Slovoobrazovanie zaimstvovannoj leksiki v jevenskom jazyke [Word Formation of the Borrowed Vocabulary in the Even Language.]. Obshhestvennye nauki. 2017. No 2-2: 375-378. 
10. Sravnitel'nyj slovar 'tunguso-man'chzhurskih jazykov. Materialy k jetimologicheskomu slovarju [Comparative Dictionary of the Tungus-Manchu Languages. Materials for the Etymological Dictionary]. V. I. L.: Nauka, 1975. 672 p.

11. Tihonov A.N. Osnovnye ponjatija russkogo slovoobrazovanija [Basic Concepts of the Russian Word Formation]. Slovoobrazovatel 'nyj slovar' russkogo jazyka: v 2 t. T. 1. M.: Rus. jaz, 1985. 856 p.

12. Fathutdinova V.G. Posledovatel'naja proizvodnost' kak universal'noe svojstvo slovoobrazovatel'nyh sistem russkogo i tatarskogo jazykov [Consistent Production as a Universal Property of Word Formation Systems of the Russian and Tatar Languages]. Uchenye zapiski Kazanskogo gosudarstvennogo universiteta. Gumanitarnye nauki. V. 148, Book 3. 2006: 154-160.

13. Cincius V.I. Ocherk grammatiki jevenskogo (lamutskogo) jazyka. Fonetika i morfologija [Essay on the Grammar of the Even (Lamut) Language. Phonetics and Morphology]. L.: Gosudarstvennoe uchebno-pedagogicheskoe izdatel'stvo Ministerstva prosveshcheniya RSFSR. Leningradskoe otdelenie, 1947. $270 \mathrm{p}$.

14. Sharina S.I. Otymennoe glagol'noe slovoobrazovanie v nizhnekolymskom govore jevenskogo jazyka [The Verbal Word Formation in the Lower Kolyma Dialect of the Even Language]. The Scientific Heritage. 2017. Vol. 2. No 9 (9): 123-125.

15. Shirshov I.A. Teoreticheskie problemy gnezdovanija [Theoretical Issues of Word Nesting]. M.: Prometej, 1999. 236 p.

16. Bölte J., Zwitserlood P., Jansma B.M., Zilverstand A. Derivational Morphology Approached with Event-related Potentials. Mental Lexicon, v. 4. No 3 (2009): 336-353.

17. Morin R. Derivational Morphological Analysis as a Strategy for Vocabulary Acquisition in Spanish. The Modern Language Journal, v. 87. No 2 (2003): 200-221.

18. Singson M., Mahony D., Mann V. The Relation between Reading Ability and Morphological Skills: Evidence from Derivational Suffixes. Reading and Writing, v. 12. No 3-4 (2000): 219-252.

19. Riehemann S.Z. Type-based Derivational Morphology. The Journal of Comparative Germanic Linguistics, v. 2. No 1 (1998): 49-77. 
20. Uriagereka Ju. Cutting derivational options. Natural Language \& Linguistic Theory, v. 19. No 4 (2001): 891-900.

\section{ДАННЫЕ ОБ АВТОРЕ}

Нестерова Елена Васильевна, научный сотрудник сектора северной филологии Институт гуманитарных исследований и проблем малочисленных народов Севера СО РАН

ул. Петровского, 1, г. Якутск, Республика Саха (Якутия), 677007, Российская Федерация

elenanesterova-2010@mail.ru

\section{DATA ABOUT THE AUTHOR}

Nesterova Elena Vasilievna, Researcher of the Sector of Northern Philology

Institute of Humanitarian Studies and Problems of Indigenous Peoples of the North of the SB RAS

1, Petrovsky Str., Yakutsk, Republic of Sakha (Yakutia), 677015, Russian Federation

elenanesterova-2010@mail.ru

ORCID: 0000-0001-5130-706X 